\title{
Estimation of the mean waiting time of a customer subject to balking: a simulation study
}

\author{
Jaejin Jang · Jaewoo Chung · Jungdae Suh • \\ Jongtae Rhee
}

\section{Erratum to: Int J Flex Manuf Syst DOI: 10.1007/s10696-006-9009-x}

The Publisher regrets that an error was introduced into the email address of J. Chung. The correct email address is: chung29@purdue.edu.

The online version of the original article can be found at http://dx.doi.org/10.1007/s10696-006-9009-x

\section{J. Jang $(\bowtie)$}

Department of Industrial and Manufacturing Engineering,

University of Wisconsin-Milwaukee, Milwaukee, WI 53201, USA

e-mail: jang@uwm.edu

\section{J. Chung}

Department of Industrial Engineering, Purdue University, West Lafayette, IN 47906, USA

e-mail: chung29@purdue.edu

\section{J. Suh}

Department Industrial Engineering, Kyungwon University, Sungnam, Korea e-mail: jdsuh@kyungwon.ac.kr

\section{J. Rhee}

Department Industrial Engineering, Dongguk University, Seoul, Korea

e-mail: jtrhee@dongguk.edu 